\title{
Hydrodynamic Simulation of Two-Phase Flow in an Industrial Electrowinning Cell with New Scheme
}

\author{
S. A. A. Pourahmadi and S. Talebi ${ }^{\dagger}$ \\ Department of Mechanical Engineering, Yazd University, Yazd, Yazd, 89195-741, Iran \\ †Corresponding Author Email: talebi_s@yazd.ac.ir
}

(Received November 30, 2019; accepted July 28, 2020)

\begin{abstract}
Electrowinning is the process of depositing copper of the electrolyte solution inside the cell to the cathode. In the present study, the hydrodynamic simulation of the electrowinning cell of Miduk Copper Complex is studied using computational fluid dynamics. The Navier-Stokes and continuity equations are considered in the form of two phases of fluid and gas, turbulent, incompressible and steady state, and the equation for copper concentration in the electrolyte is solved with consideration of its specific boundary condition. The flow turbulence is modeled using $K-\omega$ relationships. Due to large variations in the properties near cathode and anode, and also the large size of the electrowinning cell, to create a good grid, and increase the speed and accuracy of the results, global and local simulations are used together. The results of this simulation are the velocity vectors, the concentrations of acid and copper, turbulence Intensity, the amount of pressure, and the volume ratio of the oxygen phase in the entire electrowinning cell domain. For model validation, the model is compared with experiments conducted on actual cells in the industry. Results show high accuracy of this modeling technique. Then, the mass transfer coefficient values for the different electrode intervals are obtained by this modeling and the results are validated using the results of the experimental relations. In the next step, the electrolyte mixture containing different mass fractions of oxygen is sprayed into the electrowinning cell from the inlet of the simulated cell. Finally, effect of sparging different mass fraction of oxygen into electrowinning cell electrolyte, changing inlet temperature and flow rate of the electrolyte on the mass transfer coefficient is investigated by the obtained model.
\end{abstract}

Keywords: Computational Fluid Dynamics (CFD); Global and Local Simulations; Mass transfer coefficient; Two phase flow.

\section{NOMENCLATURE}

\begin{tabular}{|c|c|}
\hline C & concentration of copper \\
\hline$C_{D}$ & drag coefficient \\
\hline$C_{\text {ref }}$ & inlet and reference concentration \\
\hline $\begin{array}{l}C_{t d} \\
D\end{array}$ & $\begin{array}{l}\text { turbulent dispersion force coefficient } \\
\text { penetration coefficient }\end{array}$ \\
\hline de & $\begin{array}{l}\text { hydrodynamic diameter of electrode } \\
\text { spacing }\end{array}$ \\
\hline$E_{D}$ & diffusion activation energy \\
\hline$F$ & faraday constant \\
\hline$F_{N k}$ & interphase force \\
\hline$f$ & friction factor \\
\hline$\vec{F}_{N, \text { conc }}$ & buoyancy force \\
\hline$F_{N, \text { drag }}$ & bubble drag force \\
\hline $\overrightarrow{\mathrm{F}}_{N, t u r b}$ & turbulence dispersion force \\
\hline $\mathrm{Gr}$ & Grashof number \\
\hline$\vec{g}$ & acceleration due to gravity \\
\hline$I$ & total electrical current \\
\hline$i$ & electric current density \\
\hline & $\begin{array}{l}\text { limited electric current intensity } \\
\text { coulburn factor for heat transfer }\end{array}$ \\
\hline
\end{tabular}

$j_{H} \quad$ coulburn factor for mass transfer

$k d \quad$ mass transfer coefficient

$L \quad$ length of channel between two electrodes

$M_{C u} \quad$ molar mass of copper

$M_{\mathrm{O}_{2}} \quad$ molar mass of oxygen

$N_{C U} \quad$ copper mass transfer flux

$N \quad$ number of electrolyte phase

$n \quad$ number of sampling on each line inside

$R \quad$ gas Constant

Ra corrected Rayleigh number

$\mathrm{Re} \quad$ Reynolds number

Sc Schmidt number

$S c_{T} \quad$ turbulent Schmidt number

$S c_{u} \quad$ mass transfer flux

Sh Sherwood number

$S_{N} \quad$ copper sink or oxygen source

$t_{+} \quad$ transference number

$W \quad$ velocity difference vector

$S \quad$ width of channel between two electrodes

$z_{C u} \quad$ number of electrons that copper ion takes

$z_{O_{2}} \quad$ number of electrons released by oxygen 


\begin{tabular}{|c|c|}
\hline & ion \\
\hline$\alpha_{D}$ & volume fraction formed by the bubble \\
\hline$\alpha_{\mathrm{q}}$ & phase volume fractions \\
\hline$\beta$ & expansion coefficient \\
\hline$r_{N}$ & $\begin{array}{l}\text { intensity of the mass transfer to the phase } \\
N\end{array}$ \\
\hline$\eta$ & cathode electric current efficiency \\
\hline$\mu$ & viscosity of electrolyte \\
\hline
\end{tabular}

\section{INTRODUCTION}

Miduk copper mine is one of the largest copper complexes in Kerman province near Sarcheshmeh Copper Complex and adjacent to Shahr-e Babak. The process of copper production is globally either pyrometallurgy for copper sulfide minerals or hydrometallurgy for copper oxide minerals. In the process of hydrometallurgy, copper is extracted from the mineral by dissolution in a dilute solution of acidic electrolyte. The benefits of this method, such as low pollution and energy consumption, have led to the extensive use of this method in the industry. Copper electrowinning is a process of copper recovery from a solid electrolyte on a cathode plate, which is carried out by passing an electric current through an electrolyte to absorb copper ions on the cathode. The copper electrowinning occurs in an electrowinning cell, including electrode plates that are facing each other (Fig. 1). In Fig. 1.a, 1.b, 1.c, details of the electrowinning cell, such as inlet and outlet, are demonstrated. As can be seen, the electrolyte flow enters into the cell through holes at an angle of 45 degrees from the horizon at the bottom of the cell and releases its copper after flowing in the cell, and then, with a low concentration of copper, the flow exits the cell from its top. In the following, the dimensions are shown in the form $\mathrm{x} \times \mathrm{y} \times \mathrm{z}$, in which $\mathrm{x}$ is the size in the direction of the cell length, $\mathrm{y}$ is the size in the direction of the cell width, and $\mathrm{z}$ is the size in the direction of the cell depth. The internal dimensions of the electrowinning cell exposed to the electrolyte are $4080 \mathrm{~mm} \times$ $1200 \mathrm{~mm} \times 1335 \mathrm{~mm}$, the dimensions of the anode electrode exposed to the electrolyte are $6 \mathrm{~mm} \times$ $940 \mathrm{~mm} \times 1050 \mathrm{~mm}$, and the dimensions of the cathode electrode exposed to the electrolyte are $3 \mathrm{~mm} \times 1018 \mathrm{~mm} \times 1090 \mathrm{~mm}$. The electrode spacing is $47.5 \mathrm{~mm}$, the number of anodes is 40 , and the number of cathodes is 39. It is shown in Fig. 1.d that the flow moving between two electrodes discharges copper ions onto the cathode. Oxygen bubbles are also produced on the anode. The bubbles pass through the electrolyte solution and burst over the electrolyte free surface. It is obvious that the oxygen bubbles cause a large rotational region and this rotation, owing to its mixing nature, has a great effect on the mass transfer of copper on the cathode (AlShakarji, 2012).

The reactions (1) and

(2) are carried out in the electrowinning process. Cathode reaction:

$C u_{(\mathrm{aq})}^{2+}+2 e^{-} \rightarrow C u_{(\mathrm{s})} \quad E=+0.34 \mathrm{~V}$

$\begin{array}{ll}\mu_{o} & \text { viscosity of oxygen gas } \\ \mu_{1} & \text { electrolyte viscosity } \\ \mu_{2} & \text { oxygen viscosity } \\ \rho_{N} & \text { density of phase N } \\ \rho_{\text {ref }} & \text { reference density } \\ \rho_{1} & \text { electrolyte density } \\ \rho_{2} & \text { oxygen density } \\ \sigma & \text { stress tensor of the two-phase fluid field }\end{array}$

Anode reaction:

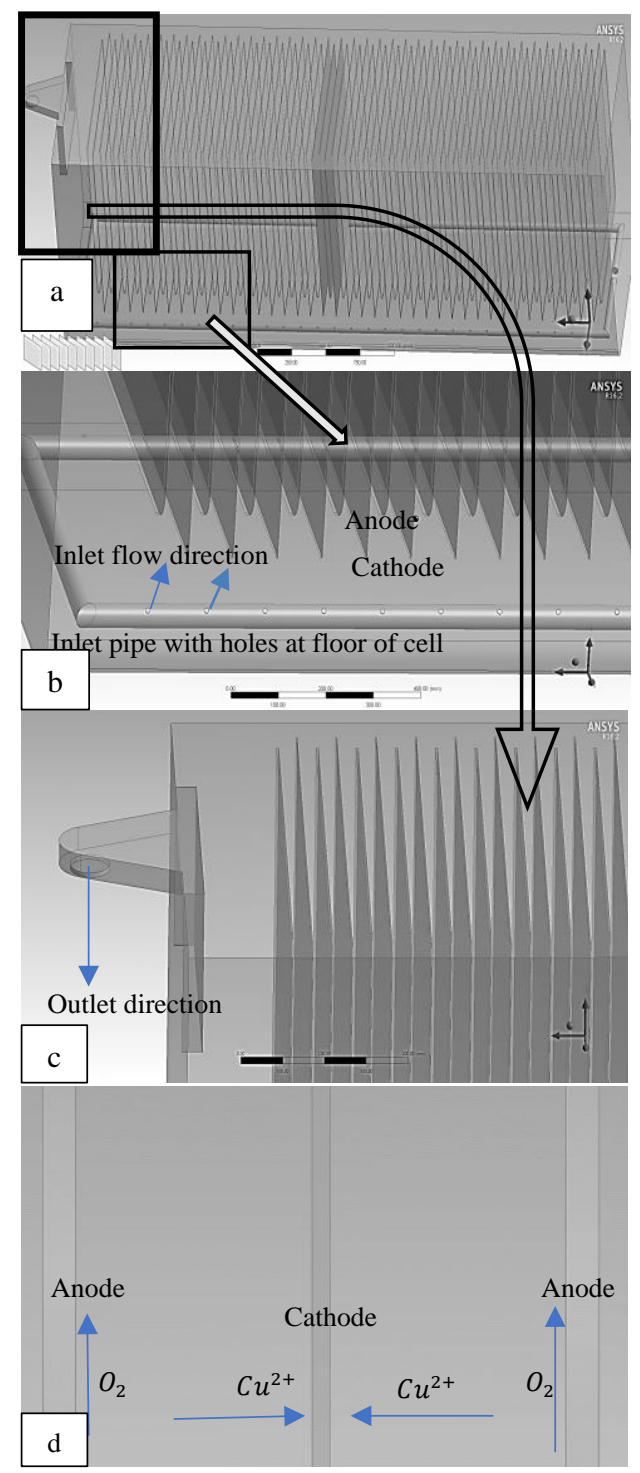

Fig. 1. a) The total space of the copper electrowinning cell, b) The inlet area of the cell, c) The outlet area of the cell, d) The space between two anodes in the middle of which the cathode is located and the copper ions sit on it.

The global electrowinning reaction is the sum of 
anode and cathode reactions plus sulfate ion.

$$
\mathrm{Cu}^{2+}+\mathrm{SO}_{4}^{2-}+\mathrm{H}_{2} \mathrm{O} \rightarrow \mathrm{Cu}+\frac{1}{2} \mathrm{O}_{2}+2 \mathrm{H}^{+}+\mathrm{SO}_{4}^{2-}
$$

With each mole of copper, one mole of sulfuric acid is added to the electrolyte and 0.5 moles of oxygen is released. In order to improve the quality and quantity of the amount of copper produced in electrowinning, there is a need for velocity and concentration fields within the electrowinning cells to control the mass transfer of copper to the cathode. One of the first studies in this field was conducted by Filzwieser (Filzwieser 2000; Filzwieser et al 2002). In the study of Filzwieser, a special laboratory electrowinning cell, including an anode and a cathode, was used to investigate the velocity and boundary layer between the two electrodes and precise laboratory data were obtained for the velocity field between the electrodes using the Laser Doppler Anemometer (LDA) method. The velocity field was applied to calculate the concentration boundary layer and the density of the limited electric current. The cell consisted of an anode and a cathode with inlet and outlet. Leahy and Schwarz (2010), with a two-dimensional fluid simulation of the velocity field, obtained a $20 \%$ error for the Filzwieser's experimental cell. Their article was one of the first papers to simulate an electrowinning cell. After that, Schwarz (2012) in a paper (Leahy and Schwarz, 2014) have studied the two-dimensional simulation of a zinc electrowinning cell and obtained the velocity and concentration field for a simple and specific cell in two-dimensional form. Leahy and Schwarz (2014) have studied the electrowinning cell more detailed. In their paper, to simulate flow and mass transfer in the electrode intervals of a pair of single sheets (an anode and a cathode) with the geometry and operating parameters of the electrowinning process of copper, twodimensional model, two-phase gas-liquid, EulerianEulerian and turbulence were employed. Their model predicted a rotational domain. In their modeling, they assumed the electrolyte fluid as the continuous phase and the oxygen gas bubbles as the discontinuous phase and the bubble diameter of about 150 microns. The turbulence model used for solving in this paper was the $K-\omega$ turbulence model. Results such as calculation of the velocity field, copper concentration contours, volumetric oxygen fraction contours, contours related to the turbulent viscosity of the flow were obtained. In this paper, the flow instability in the electrode boundary layer was also modeled. In this model, considering the long width of the anode and cathode, two-dimensional (2D) space is modeled. The important results of this paper were to prove the existence of a recirculatory flow between anode and cathode and to obtain instability in the boundary of electrodes, resulting in the mass transfer of copper ions and the quality of this transition.

In the study of industrial electrowinning cells, threedimensional (3D) modeling is required to model the effects of the edges of the electrodes, the location and geometry of the inlet and outlet, the forced flows due to the entrance and exit of the fluid from the cell, the real turbulence in the three dimensions and to assess the effects of different parameters on each other, such as the effect of the concentration and flow rate of the electrolyte entering the cell on the amount of copper produced. The detailed and thorough 3dimensional modeling of electrowinning cell is of utmost importance in the industry and should be studied. A study was conducted on 3D modeling of an industrial copper electrowinning cell by Najminoori et al (2015), which has been designed to simulate the space generated by 9 electrodes of the electrowinning cell of Sarcheshmeh cooper. In this study, a part of the Sarcheshmeh copper cell, with the assumption of the repetition of the boundary conditions of the other parts, was modeled in $3 \mathrm{D}$, and the turbulence model used was the $K-\omega$ turbulence model. Since only a fraction of space of the Sarcheshmeh copper cell was modeled in this paper, a precise investigation of the industrial cell along the cell length could not be carried out, and also for the modeling of the space between the anode and the cathode, the numerical grid on the whole of a cell alone would not yield exact answers. The reason that a part of the cell was modeled was that for a precise solution, there was a need for a very fine, to a smaller extent than the concentration boundary layer, numerical grid near the electrodes. This numerical grid is extremely large owing to the great length and width of the electrodes and the large number of them in the cell volume for being precise. On the other hand, solving the problem is very slow due to the creation of effective floating forces and the turbulence of the convergence speed. As a result, a new solution methodology is needed to precisely solve the 3D problem. In order to adopt an approach that can be used to solve the problem of electrowinning with high speed and precision, a thorough literature review was conducted, but a proper one was not found. Therefore, studies on other problems similar to electrowinning, especially copper refining, have been studied so that it can be applied to the problem of electrowinning.

In Kemminger and Ludwig's article (Kemminger and Ludwig 2013), the simulation of a full-scale copper electrorefining tankhouse cell was performed. The copper electrorefining tankhouse cell is similar to the electrowinning cell, with the difference that other process reactions occur that are different from those of the electrowinning process. In this paper, two types of simulations were used in parallel to perform a modeling with high speed and precision. The local simulation modeled the region between the anode and cathode electrodes with high precision and obtained its initial and boundary conditions from a global simulation that modeled the full-scale cell with moderate precision. With this method, the Kemminger and Ludwig simulation (Kemminger and Ludwig 2013) managed whole copper electrorefining tankhouse cell modeling with high speed and precision. In Lou et al. paper (Luo et al 2018), flow fields were visualized by particle image velocimetry in bench-scaled zinc electrolysis cell. Flow patterns were dominated by bubbleinduced flow rather than electrolyte feeding. In this paper it has been shown that rising bubbles are the main cause of local turbulence near electrode surfaces. In the next section of the studies, the mass 
transfer coefficient will be investigated. The factor that summarizes the quantity and quality of copper deposited on the cathode is the mass transfer coefficient. By having a mass transfer coefficient in an industrial electrowinning cell, it is possible to obtain the amount of copper produced under operating conditions. Furthermore, if this coefficient is available for any point on the surface it can prevent surface unevenness, nodule formation, and cathode quality problems. In order to predict the mass transfer coefficient in electrowinning cells, it is of necessary to have the velocity and concentration fields inside them. Many experiments have been conducted on the mass transfer in the electrowinning cell, some of which are discussed below.

Sigrist and Dossenbach (1979) studied the mass transfer in a specific vertical electrowinning cell inside which the air was sparged. They showed that the mass transfer coefficient was related to volume fraction of air in the electrolyte. In this paper, the Sherwood number was linked to the corrected Archimedes number by experiment. Studies conducted by a number of researchers (Fisher and Hughes 1971; Raju et al.1967; Raju et al. 1979) have investigated the use of fluid flow mixers, fluid flow pulsers, electric current recirculation, and flotation, respectively, as some of the strategies to increase mass transfer. In another study, Subbaiah et al. (1995) investigated the mass transfer in a specific electrowinning cell in which the fluid stream became turbulent using a turbulence promoter. The presence of the promoter caused a 100\% increase in the mass transfer coefficient in this cell and the relationship between the mass transfer coefficient and the promoter specifications was obtained.

Graydon and Kirk (2001) demonstrated that the rise of oxygen in the electrode space caused recirculation in the region, which had a large effect on the mass transfer. Najim (2016) obtained the mass transfer coefficient of a specific electrowinning cell for different temperatures and concentrations at certain laboratory intervals by using the limiting current technique (LCT). In their paper, a relation for Sherwood number that related to the root of the product of the Grashof number and the Schmidt number was presented. Beukes and Badenhorst (2009) investigated the relationships, equations, and mass transfer coefficients of various industrial cells in a study. Cifuentes and Arriagada (2008) investigated factors such as temperature, electric current, concentration, and rotation speed of the bed on the mass transfer of an electrowinning cell with a moving bed and showed that increasing the temperature and concentration of copper increased the mass transfer.

Najminoori et al. (2019) examined the effect of the magnetic field with designing full-scale experiment considering factors such as copper and iron concentration, electric current density, presence, and absence of magnetic field, and thickness and morphology of structures formed on copper. Their paper demonstrated that, in the presence of a magnetic field, the mass transfer coefficient decreased due to the presence of intrusive iron ions; however, the material deposition was more uniform.
Using an experimental procedure, Soliman et al. (2011) obtained Sherwood number to calculate mass transfer in an electrowinning cell with rotating cylinder electrodes. Using analytical and experimental studies, Coleman (Coleman and Roy 2014) exposed a specific test cell with a small electrode interval to ultrasonic waves, obtained its mass transfer relationships, and showed that the use of ultrasonic waves would increase the mass transfer in the cell. Considering studies on mass transfer coefficient in the electrowinning cell, it can be concluded that most studies have experimentally investigated the mass transfer coefficient. However, by modeling the cell, the mass transfer coefficient can be obtained both on the average of the whole cell and locally on each point of the cell.

In the present paper, modeling a 3D full-scale electrowinning cell using the global and local modeling method for solving the problems of accuracy and time-consuming. The local simulation, such as that of Kemminger and Ludwig, is a highly precise modeling of the region between the cathode and the anode, due to the very fine numerical grid in this area. The global simulation is a moderateprecision modeling for the region between the anode and cathode and highly precise modeling for the rest of the cell with respect to the physics of the problem and its moderate numerical grid for these areas. It is worth mentioning that this method was first used in electrowinning cells. In order to evaluate the accuracy of this method, the model is compared with the overall modeling and for validation purposes, the modeling results are compared and with the real cell test results that have been conducted in the Miduk Electrowinning Unit. Since the model is completely performed with fewer assumptions, the model would be more realistic and the boundary conditions of the local regions would be more accurate.

In the following, it is attempted to investigate, for the first time in the industrial scale, the mass transfer in an electrowinning cell according to the industrial modeling method. Due to the practical importance of the mass transfer coefficient of the cell for the quantity and quality of copper production in the cell, this coefficient is obtained for different operating conditions and has been compared with the experimental relationships presented in other studies. In the next important step, the mass transfer coefficient is obtained locally on the cathode and investigated.

\section{Modeling}

To begin the simulation, step-by-step measures have been taken in the design software of Ansys CFX (ANSYS CFX-Solver Theory Guide). The first step in the simulation is modeling of the geometry of the electrowinning cell of Miduk Copper Complex based on existing executive maps. Fig. 2 shows the geometry of the modeled electrowinning cell.

Because the electrowinning cell is both physically and geometrically symmetric, in Fig. 2.a, a geometric model of the half of the cell is demonstrated. The global modeling has been performed on the geometry 
of Fig. 2.a. Fig. 2.b represents a part of the cell that is modeled locally. This section shows the distance between the two anodes, including the cathode, the wall, the intracellular space, the tube, and the inlet nozzle. Fig. 2.c is derived from the removal of the local domain from the global domain.

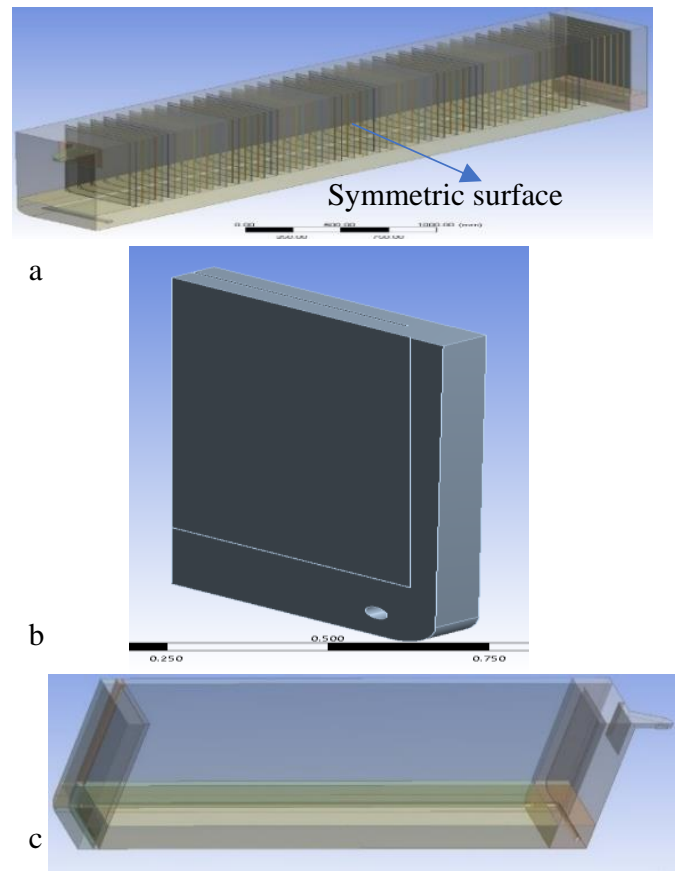

Fig. 2. Geometric modeling of the electrowinning cell of Miduk Copper Complex, a) Global simulation, b) Local simulation of the gap between the two anodes, c) Global geometry minus electrodes spaces.

The next step in the simulation is the generation of a mesh or numerical grid on the solution domain. Meshing has important rules to follow:

- The mesh should become finer or coarser in different domains proportional to the gradient of concentration or velocity.

- The meshing is as close as possible to the hexahedral in the structured meshes and to the tetrahedral in the unstructured meshes.

The meshing in the geometry of the electrowinning cell has been done with these considerations and, to increase the solving speed, hybrid meshing of structured and unstructured meshes has been employed in different domains. The number of meshes during the solution was considered variable for the faster convergence and the mesh density increased during the solution based on the concentration gradient in four stages. The problem was initially started with a mesh number of $10^{6}$ and reached to a maximum mesh number of $6.3 \times 10^{6}$ at the end solution. Observing these factors makes it possible to have the highest accuracy in solving and solving convergence with the least number of meshes. Fig. 3 shows the meshing at the gap between the two cathodes. Fig. 3.a depicts the finest meshing for global simulation while Fig. 3.b displays the finest meshing for local simulation in a plane perpendicular to the electrodes in the middle of the cell.

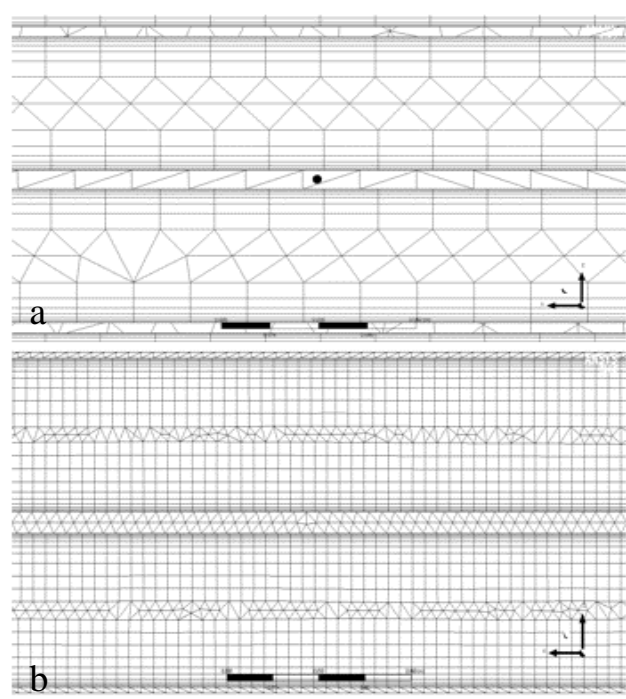

Fig. 3. Mesh between two cathode plates, anode located in the middle, a) global modeling, b) local modeling.

The first layer of the meshes on the electrodes in both simulations has a width of $300 \mu \mathrm{m}$ because the concentration boundary layer is approximately $550 \mu \mathrm{m}$. The thickness of the concentration boundary layer near the electrodes in this paper is based on the results of the modeling and also experimentally obtained in the paper by König et al. (2011). The mesh layers are expanded with the appropriate geometric coefficient on the electrodes. This magnitude of expansion on both the anode and cathode makes it possible to include most of the domain with a high concentration and velocity gradients, and also to create an appropriate layout of 2 layers of meshes in the concentration boundary layer.

\section{GOVERNING EQUATIONS}

The technique used to simulate the two-phase flow in this cell is the Eulerian-Eulerian model. This model solves the momentum and continuity equations for each phase. The description of multiphase flow as a continuous and interpenetrating medium utilizes the concept of phase volume fractions, which is represented by $\alpha_{\mathrm{q}}$. The volume fraction represents the occupied space of each phase, and the laws of conservation of mass and momentum are separately satisfied for each phase. The relation that exists with respect to the definition of volume fractions for a two-phase flow is Eq. (Geankoplis 2003):

$\alpha_{1}+\alpha_{2}=1$

If the problem is continuous, the momentum equations are generally expressed using Eq. (Geankoplis 2003): 
$\frac{\partial\left(\rho_{N} \alpha_{N} u_{N i}\right)}{\partial x_{i}}=S_{N}$

Where $N=1$ and 2 represent the electrolyte phase and oxygen gas respectively. $\rho_{N}$ is the phase density, $S_{N}$ is the term for the copper sink in the cathode or the oxygen source in the anode, which is defined by Faraday's relations in their boundary conditions and will be described in the Boundary Condition section.

The momentum relationship of each phase is found by Eq. (6) (Geankoplis 2003):

$\frac{\partial}{\partial x_{i}}\left(\rho_{N} \alpha_{N} u_{N i} u_{N k}\right)=\alpha_{N} \rho_{N} g_{k}+F_{N k}-\delta_{N}\left\{\frac{\partial p}{\partial x_{k}}-\right.$

$\left.\frac{\partial \sigma_{C k i}^{D}}{\partial x_{i}}\right\}$

Where $\sigma$ is the stress tensor of the two-phase fluid field and it's summarized with $\frac{\partial \sigma_{C k i}^{D}}{\partial x_{i}}=\mu_{N} \frac{\partial^{2}\left(\alpha_{N} u_{N k}\right)}{\partial x_{i}{ }^{2}}$

In Eq. (6), $\delta_{1}=1, \delta_{2}=0$, and $F_{N k}$ is the interphase force acting on the $N$ phase from other phases in the $k$ direction. In accordance with Newton's third law, Eq. (7) is (Geankoplis 2003):

$\sum_{N} F_{N k}=0$

Using the continuity equation for one phase among other phases, Eq. (6) for the single-phase $N$ is simplified to the Eq.

Najminoori et al. 2015):

(8) (Geankoplis 2003;

$\rho_{N} \alpha_{N}\left\{u_{N i} \frac{\partial u_{N k}}{\partial x_{i}}\right\}=\alpha_{N} \rho_{N} g_{k}+F_{N k}-Y_{N} u_{N k}-$

$\delta_{N}\left\{\frac{\partial p}{\partial x_{k}}-\frac{\partial \sigma_{C k i}^{D}}{\partial x_{i}}\right\}$

Where $Y_{N}$ is the intensity of the mass transfer to the phase $N . F_{N k}$ is obtained from the resultant of the four forces present in Eq. (9) (Geankoplis 2003; Najminoori et al. 2015) .

$F_{N k}=F_{N, \text { drag } k}+F_{N, \text { turb } k}+F_{N, \text { grav } k}+F_{N, \text { conc } k}$

For the bubble drag force in the control volume where the volume fraction of $\alpha_{D}$ is formed by the bubble, the simplified Schiller-Newman relation is presented in Eq. (10) (Najminoori et al. 2015):

$F_{N, \operatorname{drag~} k}=-\frac{3}{4} \frac{C_{D}}{d} \rho_{C} \alpha_{D}\left|W_{k}\right| W_{k}$

Where $W$ is the velocity difference vector between the other phase and the phase $N$ and the drag coefficient is calculated using Eq.

(Najminoori et al. 2015):

$\mathrm{C}_{\mathrm{D}}=\frac{24}{\mathrm{Re}}\left(1+0.15 \mathrm{Re}^{0.687}\right)$

The difference in the concentration created in a continuous phase can cause a difference in density and therefore the difference in the weight of different fluid parts. As a result, the gravitational force that affects this difference in weight enters the buoyancy force to the continuous phase, which is expressed by Eq. (12) (Leahy and Schwarz 2014):

$\vec{F}_{N, \text { conc }}=\delta_{N, 1} \alpha_{N}\left[-\rho_{N} \vec{g} \beta\left(C-C_{\text {ref }}\right)\right]$

Where $\beta$ is the concentration expansion factor, $C$ is the concentration of copper, and $C_{\text {ref }}$ is the concentration of copper at the inlet. In the momentum transfer equation, the part of the force is due to the difference in concentration, therefore, the other relation which must be solved and is coupled to the momentum equation is the relation for species transfer, which is related to the concentration by Eq. (13) (Leahy and Schwarz 2014).

$\vec{\nabla} \cdot\left(\alpha_{1} C_{C u} \vec{U}_{1}\right)=\vec{\nabla} \cdot\left(\alpha_{1}\left(\rho_{1} D_{1}+\frac{\mu_{T, 1}}{S c_{T}}\right) \vec{\nabla}\left(\frac{C_{C u}}{\rho_{C u}}\right)\right)+$ $S_{C u}$

This equation shows how copper ions are displaced by the presence of concentration differences in the fluid field and, in fact, mass is transferred. $D, S c_{T}$, and $S c_{u}$ are respectively the copper ion penetration coefficient, the turbulent Schmidt number, and the term for the mass transfer flux sink in the cathode or the mass transfer flux source in the anode.

For the term arising from the density variation buoyancy force, the Eq. (14) holds (Najminoori et al. 2015):

$\vec{F}_{N, \text { grav }}=\alpha_{N}\left(\rho_{N}-\rho_{\text {ref }}\right) \vec{g}$

Where $\rho_{N}$ is the density of phase $N, \rho_{\text {ref }}$ is the reference density or the electrolyte inlet, and $\vec{g}$ is the acceleration due to gravity. Finally, the result of the turbulence dispersion force is obtained by Eq. (15) (Leahy and Schwarz 2014; Najminoori et al. 2015)):

$\vec{F}_{N, t u r b}=(-1)^{N} C_{t d} \rho_{N} K \vec{\nabla} \alpha_{N}$

Where $C_{t d}$ is the turbulent dispersion force coefficient. In a two-phase flow, the flow of each phase can be either laminar or turbulent. In the flow of the electrowinning cell, since the Reynolds number is small for gas and liquid (Najminoori et al. 2015), the flow seems to be laminar, but due to the large natural flow stemming from the difference in concentration and the drag of the bubble, it has a very large Rayleigh number; hence, the flow of the electrolyte phase is assumed to be turbulent while the flow of the gas phase is assumed to be laminar owing to its small bubbles (Najminoori et al. 2015).

There are different models for investigating turbulence. One of the best of them for the electrowinning cell is the two-equation $K-\omega$ model due to the presence of walls and the dominant natural flows. The turbulence model equations for a phase are Eq. (16) (Geankoplis, 2003):

$\frac{\partial(\rho \omega)}{\partial t}+\frac{\partial\left(\rho u_{j} \omega\right)}{\partial x_{j}}=$

$\frac{\alpha \omega}{K} P-\beta \rho \omega^{2}+\frac{\partial}{\partial x_{j}}\left[\left(\mu+\frac{1}{\sigma_{\omega}} \rho \frac{K}{\omega}\right) \frac{\partial(\omega)}{\partial x_{j}}\right]+$ $\frac{\rho \sigma_{d}}{\omega} \frac{\partial(K)}{\partial x_{j}} \frac{\partial(\omega)}{\partial x_{j}}$

$\frac{\partial(\rho K)}{\partial t}+\frac{\partial\left(\rho u_{j} K\right)}{\partial x_{j}}=$

$\rho P-\beta^{\prime} \rho \omega K+\frac{\partial}{\partial x_{j}}\left[\left(\mu+\frac{1}{\sigma_{K}} \rho \frac{K}{\omega}\right) \frac{\partial(K)}{\partial x_{j}}\right]$

$\mu_{t}=\rho \frac{K}{\omega}$ and constants are defined by Eq. 
$\beta^{\prime}=0.09$

$\alpha=\frac{5}{9}$

$\beta=0.075$

$\sigma_{K}=2$

$\sigma_{\omega}=2$

In order to examine the mass transfer in an electrowinning cell, dimensionless numbers proposed for mass transfer should be studied. Species are transferred from the bulk solution to the electrode surface in three ways. First way Convection, including forced and natural modes induced by density differences. Second way Diffusion induced by the concentration gradient of copper. Third way, Ionic migration induced by electric field. Due to the large amount of neutral electrolyte in the electrowinning process, the role of ion migration is negligible, and copper only reaches the electrode surface through two effective modes of convection and diffusion. The mass transfer flux of $\mathrm{Cu}, \mathrm{N}_{C U}$, is expressed by Eq. (18) (Beukes and Badenhorst (2009):

$N_{C U}=\frac{M_{C u}}{A} \frac{d M}{d t}=\frac{I M_{C u}}{n F A}=\frac{M_{C u} i}{n F}$

In the diffusion boundary layer, for a completely stable problem assuming complete mixing, the mass flux can be calculated by Eq. (19) (Beukes and Badenhorst (2009):

$N_{C U}=-D \frac{d C_{c u}}{d x}$

Using Eqs. (18) and (19), Eq. (20) is obtained for the layer close to the electrode (Beukes and Badenhorst (2009)).

$i=-n \times F \times \frac{D}{M_{C u}} \frac{d C_{c u}}{d x}$

The mass transfer coefficient is defined as Eq. (Beukes and Badenhorst 2009).

$k d=\left.\frac{-D}{\left(C_{c u(b u l k)}-C_{c u(s u r f a c e)}\right)} \frac{d C_{c u}}{d x}\right|_{x=0}$

The unit of mass transfer coefficient is $\frac{m}{s}$. In electrowinning cells, this unit is very large and the mass transfer coefficient is usually expressed in micrometers per second. The fluid flow relationship is simplified as Eq. (22) (Beukes and Badenhorst (2009).

$i=\frac{n \times F \times k d}{M_{C u}} \times\left(C_{c u(b u l k)}-C_{c u(\text { surface })}\right)$

When all the copper ions that reach the electrode surface are absorbed by the cathode or the mass transfer of copper ions to the electrode surface is reduced, a limiting intensity occurs for copper production. The limited electric current is the electric current that does not change with increasing potential in the reaction intensity. For this reason, the determination of the limited electric current of the diffusion is important for the design and optimization of the reactor. When the electric current intensity is limited, all the copper concentrations in the surface are consumed, resulting in Eq. (23) (Beukes and Badenhorst (2009):

$i_{\lim }=n \times F \times k d \times C_{c u(b u l k)}$
Two points can be deduced from this relationship. First, increasing the bulk concentration can increase the amount of the limiting electric current that is obtained by optimizing the soluble extraction (SX). Second, increasing the mass transfer coefficient of the cell can increase its limiting electric current which is a function of the cell's hydrodynamics, inlet electrolyte characteristics, operating temperature, and so on. Mass transfer coefficients are usually obtained by empirical relationships based on dimensionless numbers. In what follows, some of the non-dimensionless numbers and parameters used in this study are presented in Table 1 .

Numerous empirical relationships have been presented in various articles on mass transfer in relation form of Eq. (24) (Beukes and Badenhorst (2009); Gendron and Ettel 1975; Najim 2016; Raju et al. 1979; Rao 1974):

$\mathrm{Sh}=C \cdot \operatorname{Re}^{n} \cdot \mathrm{Sc}^{m}\left(\frac{d e}{L}\right)^{p}$

Table 1 Important parameters used to obtain the mass transfer coefficient and Sh number

\begin{tabular}{|c|c|c|}
\hline $\begin{array}{l}\text { Parameters of } \\
\text { Relationships }\end{array}$ & Relation & $\begin{array}{c}\text { Parameter } \\
\text { with } \\
\text { characteristic } \\
\text { s of Table } 2 \\
\end{array}$ \\
\hline Reynolds number & $\operatorname{Re}=\frac{\rho \mathrm{v} L}{\mu}$ & 2500 \\
\hline Schmidt number & $\mathrm{Sc}=\frac{v}{D}$ & 1555 \\
\hline Grashof number & $\begin{array}{l}\mathrm{Gr} \\
=\frac{g \cdot \beta \cdot\left(C_{s}-\right.}{v^{2}}\end{array}$ & $2.5 \times 10^{8}$ \\
\hline $\begin{array}{c}\text { Corrected Rayleigh } \\
\text { number }\end{array}$ & $\begin{array}{l}\mathrm{Ra} \\
=\frac{g \cdot \beta \cdot \dot{m} \cdot H^{4}}{v^{2} \cdot D}\end{array}$ & $5.6 \times 10^{14}$ \\
\hline $\begin{array}{l}\text { Hydrodynamic } \\
\text { diameter of } \\
\text { electrode spacing }\end{array}$ & $d e=\frac{2 L S}{(L+S)}$ & $0.089(\mathrm{~m})$ \\
\hline
\end{tabular}

In the study conducted by Gendron and Ettel (1975), the type of fluid flow inside a cell is illustrated by the diagram presented in Fig. 4. Therefore, the Reynolds number is the indicator of the laminar or turbulent fluid flow and the Reynolds number along with the cathode mass transfer coefficient can determine whether the turbulent fluid flow is the inlet area or fully developed.

Gendron and Ettel used silver ions for tracing in their paper (Gendron and Ettel 1975). Consequently, the diagram is provided for the mass transfer coefficient of silver ions. The copper mass transfer coefficient is related to the silver mass transfer coefficient by Eq. (25) (Gendron and Ettel 1975).

$\frac{k_{C u^{2+}}}{k_{A g^{+}}}=\left(\frac{D_{C u^{2+}}}{D_{A g^{+}}}\right)^{\frac{3}{4}}=\left(\frac{r_{A g^{+}}}{r_{C u^{2+}}}\right)^{\frac{3}{4}}=1.406$

If there is a laminar fluid flow over the plane, the 
dimensionless Sherwood number can be calculated by Eq. (26).

$\mathrm{Sh}_{1}=1.85 \times\left(\operatorname{Re} \times \mathrm{Sc} \times \frac{D_{h}}{L}\right)^{\frac{1}{3}}$

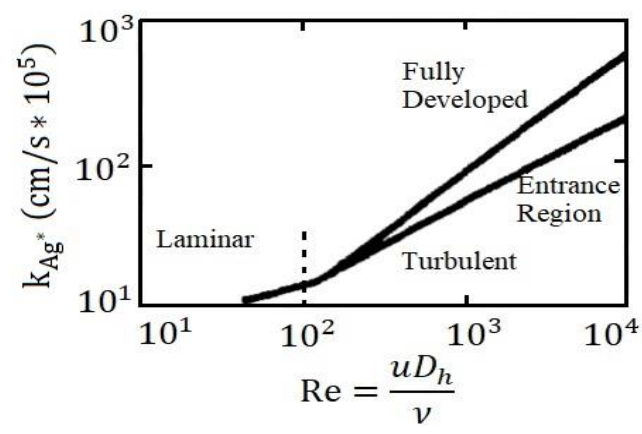

Fig. 4 Diagram determines the type of fluid flow between electrodes inside the cell based on the Reynolds number and mass transfer coefficient (Gendron and Ettel 1975).

If the fluid flow is turbulent, owing to the confined flow between the two electrode plates, there are two types of fully developed or undeveloped fluid flow. For undeveloped turbulent fluid flow, empirical Eq. (27) is provided for Sherwood number (Beukes and Badenhorst (2009); Gendron and Ettel 1975).

$\mathrm{Sh}_{2}=0.0356 \times \operatorname{Re}^{0.8} \times \mathrm{Sc}^{\frac{1}{3}}$

And for the developed turbulent fluid flow, Eq. (28) can be used (Beukes and Badenhorst (2009); Gendron and Ettel 1975).

$\mathrm{Sh}_{3}=0.0789 \times f^{\frac{1}{2}} \times \operatorname{Re} \times \mathrm{Sc}^{\frac{1}{4}}$

$\mathrm{f}$ in Eq. (28) is the friction factor which can be obtained from Eq.

(29) (Beukes and Badenhorst (2009); Gendron and Ettel 1975).

$f=\frac{0.079}{\operatorname{Re}^{\frac{1}{4}}}$

Eq.

(30) is another well-known relation obtained by the Chilton-Coulburn method and used for mass transfer in laminar fluid flow (Beukes and Badenhorst (2009); Gendron and Ettel 1975).

$j_{D}=j_{H}=0.023 \mathrm{Re}^{-0.2}$

Where $j_{D}$ and $j_{H}$ are the Coulburn factors for heat and mass transfer, respectively. For the Coulburn mass transfer factor, Eq. (31) exists (Beukes and Badenhorst (2009); Gendron and Ettel 1975).

$j_{D}=\frac{\mathrm{Sh}}{\operatorname{Re} \times(\mathrm{Sc})^{\frac{1}{3}}}$

Consequently, Sherwood number is in the form of Eq. (32) (Beukes and Badenhorst (2009); Gendron and Ettel 1975):

$\mathrm{Sh}_{4}=0.023 \mathrm{Re}^{0.8} \mathrm{Sc}^{\frac{1}{3}}$

In the Miduk industrial electrowinning, given that the Reynolds number ranges above 2300 and the copper mass transfer coefficient is less than $6 \mathrm{\mu m} / \mathrm{s}$ as shown in Fig. 2, it can be concluded that the fluid flow inside the cells and between the electrodes is in the undeveloped turbulent region. The average mass transfer coefficient to the electrodes in the electrowinning cell is related to Sherwood number by Eq. (33) :

$k d_{n}=\operatorname{Sh}_{\mathrm{n}} \times \frac{D}{d e}$

In Eq. (33), $\mathrm{n}$ represents the type of relationship used for the Sherwood number, which actually determines the type of flow. Equivalent diameter in Eq. (33), de, is obtained for electrowinning cells using Eq. (34) (Beukes and Badenhorst (2009); Gendron and Ettel 1975).

$d e=\frac{2 L S}{(L+S)}$

In Eq. (34), $L$ and $S$ are the length and width of the channel between the two electrodes, respectively.

In order to consider the temperature variations of the electrolyte inside the cell, relationships of the density, viscosity, and the diffusion coefficient of copper in the electrolyte are required. The electrolyte density is obtained according to Price's relation, Eq. (35) (Werner 2017).

$\rho=1018.56+0.151 C_{C u}+0.54 C_{\mathrm{H}_{2} \mathrm{SO}_{4}}-0.59 T$

The viscosity of oxygen gas as a function of temperature can be calculated by Sutherland's viscosity law, Eq. (36) (Sutherland 1893)

$\mu_{o}=C \frac{T^{\frac{3}{2}}}{0.555 T+120}$

For the viscosity of electrolyte as a function of temperature, Eq. (37) exists (Moats et al. 2000).

$\mu=\frac{1}{1000}\left(-1989.46+0.010353 C_{C u^{2+}}+\right.$

$\left.0.0014685 C_{\mathrm{H}_{2} \mathrm{SO}_{4}}+1983.72 e^{\frac{1}{T}}\right)$

For the calculation of the diffusion coefficient of copper inside the electrolyte as a function of temperature, Eq. (38) can be used (Moats et al. 2000).

$D=D_{0} e^{-\frac{E_{D}}{R T}}$

Where $E_{D}$ is the diffusion activation energy, $R$ is the gas Constant and the exponent.

\section{PARAMETERS AND BOUNDARY Conditions OF The Cell}

Boundary condition can be divided into two types of non-slip condition and free slip condition in terms of limitations; the non-slip condition is defined by $U_{\text {Wall }}=0$ and the free-slip condition is defined by Eq. (39).

$\tau_{w}=0, U_{n, \text { Wall }}=0$

All cell, anode, and cathode walls have the non-slip boundary condition for the electrolyte phase and the free-slip condition for the gas oxygen phase. In numerous papers with experimental validations, the 
free-slip condition for gas bubbles is considered in a two-phase flow (Pourtousi et al. 2015).

The free surface of the cell has a degassing boundary condition. This condition for the electrolyte, that is, continuous phase, plays the role of a wall with the free-slip condition, and for gas bubbles, which is the discrete phase, is acting similar to a co-speed outlet with the gas released to the free surface. As a result, the oxygen bubble leaves the domain as fast as it reaches the surface.

The anode and cathode have the non-slip wall boundary condition for the electrolyte phase and the free-slip wall for the gas oxygen phase, and since the oxygen generation reaction occurs in the anode, it is also the oxygen source.

The amount of mass that is absorbed from or emitted to the fluid adjacent to the electrode during oxidation due to the electric field is related to the electric current of the cell according to Faraday's law. The total volume of oxygen produced in the anode is linearly related to its electrical current. According to Faraday's law, the apparent flow rate of the overall gas produced is obtained by Eq.

(40) (AlShakarji 2012; Najminoori et al. 2015).

Flux $_{O X}=\frac{I M_{O_{2}}}{z_{O_{2}} F}$

where $I$ is the total electrical current on the anode and cathode surfaces, $F$ is Faraday constant, $M_{\mathrm{O}_{2}}$ is molar mass of oxygen, and $z_{\mathrm{O}_{2}}$ is the number of electrons released by oxygen ion. For the boundary condition of the cathode, there is also the Eq. (41) (AlShakarji, 2012; Najminoori et al. 2015):

$N_{C u}=\eta \frac{I M_{C u}}{z_{C u} F}$

Where $M_{C u}$ is the molar mass of copper, and $z_{C u}$ is the number of the electrons that the copper ion takes and $\eta$ is the cathode electric current efficiency, which is usually $88-92 \%$, and is related to the working conditions of the cells. It is worth mentioning that electrolyte has been considered as a variable composition mixture comprising two combinations of copper ions and dilute sulfuric acid to indicate a change in the mass fraction of copper.

For the inlet boundary condition, a steady constant flow rate with real industry conditions is considered, which only contains electrolyte with a real copper concentration. This inlet is removed by diagonal tubular holes in the bottom corner of the tube. The phase condition of the outlet material is considered the only electrolyte with a real copper concentration. There is a vertical longitudinal surface in the middle of the electrowinning cell, in which both physical and geometric symmetries are present. The boundary condition of symmetry is established according to the relations Eq. (42) (Najminoori et al. 2015):

$\frac{\partial \phi}{\partial n}=0$ and $U_{n}=0 ;$

Where $\phi$ includes all scalar parameters such as pressure, concentration, and volume fraction. In Table 2, the real industrial parameters required for the Miduk electrowinning cell model are presented.
Table 2 Industrial parameters of Miduk

\begin{tabular}{|c|c|}
\hline Parameter & Value \\
\hline Electric current density (i) & $196 \frac{\mathrm{A}}{\mathrm{m}^{2}}$ \\
\hline Inlet flow rate & $1.5 \frac{\mathrm{lit}}{\mathrm{s}}$ \\
\hline Electrolyte density $\left(\rho_{1}\right)$ & $1200 \frac{\mathrm{kg}}{\mathrm{m}^{3}}$ \\
\hline Oxygen density $\left(\rho_{2}\right)$ & $1.2 \frac{\mathrm{kg}}{\mathrm{m}^{3}}$ \\
\hline Electrolyte viscosity $\left(\mu_{1}\right)$ & $1.18 \times 10^{-3} \frac{\mathrm{kg}}{\mathrm{m} \cdot \mathrm{s}}$ \\
\hline Oxygen viscosity $\left(\mu_{2}\right)$ & $2.18 \times 10^{-5} \frac{\mathrm{kg}}{\mathrm{m} \cdot \mathrm{s}}$ \\
\hline Penetration Coefficient $(\mathrm{D})$ & $8.62 \times 10^{-10} \frac{\mathrm{m}^{2}}{\mathrm{~s}}$ \\
\hline transference number $\left(t_{+}\right)$ & 0.0849 \\
\hline Expansion coefficient $(\beta)$ & $0.0019 \frac{\mathrm{m}}{\mathrm{kg}}$ \\
\hline $\begin{array}{c}\text { Inlet and reference } \\
\text { concentration }\left(C_{r e f}\right)\end{array}$ & $36 \frac{\mathrm{kg}}{\mathrm{m}^{3}}$ \\
\hline Acid concentration & $180 \frac{\mathrm{kg}}{\mathrm{m}^{3}}$ \\
\hline
\end{tabular}

The numerical solution method used in the Ansys CFX software is based on the fully coupled solver algorithm (ANSYS CFX-Solver Theory Guide). Because in this algorithm all the equations are solved coupled together in an implicit manner, more memory is occupied, but it has faster convergence than Simplec algorithm. The first-order upwind discretization scheme has been employed for turbulence, momentum, continuity and concentration equations, which creates a higher convergence. In order to increase the speed, the 8-part parallel processing on an 8-core processor at the speed of 2.6 $\mathrm{GHz}$ and RAM memory of 16GB has been used.

\section{VALIDATION}

For validation of the model, the mass concentration of copper ions in the Miduk electrowinning cell is measured in two lines. This measurement was done by removing small specimens by micropipette and using the titration method. In the titration, potassium iodide was added to the specimen and then titrated with sodium thiosulfate. In this way, copper ions are reduced and deposited. The reaction is carried out according to the following reaction

(43):

$2 \mathrm{Cu}^{2+}+4 \mathrm{I}^{-} \rightarrow 2 \mathrm{CuI}(\mathrm{s})+\mathrm{I}_{2}$

The iodine produced by sodium thiosulfate was measured and then the amount of copper ions was measured by stoichiometry. The reaction is carried out according to the following reaction

$2 \mathrm{Na}_{2} \mathrm{~S}_{2} \mathrm{O}_{3}+\mathrm{I}_{2} \rightarrow \mathrm{Na}_{2} \mathrm{~S}_{4} \mathrm{O}_{6}+2 \mathrm{NaI}$

The starch glue has been used to accurately determine the endpoint of the titration. The amount of uncertainty in the results of testing the 
concentration of copper by titration was reduced as a result of twice repetition for each point, the use of starch glue, the use of the micropipette for small sample sampling, testing with precision instruments, and conducting the tests at temperatures of about 25 degrees and the relative standard uncertainty for titration is about $0.1 \%$ (Reining 2018).

The experimental work was carried out in two stages. The difference between the stages is that each one was conducted in two different times with a multiday interval, in two different cells, between two electrodes with different locations, and different inlet and outlet conditions and electrical current in terms of production. Each of these steps, shown below with $\mathrm{A}$ and $\mathrm{B}$, was conducted in two different days, and thus with different cell conditions. At each stage, 2 different lines in the cell and between the same two electrodes were considered. The first line is a horizontal line between the cathode and the anode at a certain distance from the electrolyte surface and the second line is a vertical line from the electrolyte surface to the cell floor and in the middle of the cathode and anode electrodes. For each of these stages and lines, samples were taken at several points by a device made for sampling (including a micropipette and two special millimeter rulers and a base) and testing the copper concentration was carried out with precision on them. The flow rate conditions, the inlet and outlet concentrations, the electric current density, and distance of the horizontal line from of the electrolyte level are presented in Table 3 for both stages A and B.

Table 3 Different parameters in steps A and B

\begin{tabular}{|c|c|c|}
\hline Parameters & Stage A & Stage B \\
\hline $\begin{array}{c}\text { Electrolyte flow rate } \\
\text { entering all cells }\end{array}$ & $330 \frac{\mathrm{m}^{3}}{\mathrm{hr}}$ & $300 \frac{\mathrm{m}^{3}}{\mathrm{hr}}$ \\
\hline $\begin{array}{c}\text { Cooper concentration of } \\
\text { inlet electrolyte }\end{array}$ & $34.6 \frac{\mathrm{kg}}{\mathrm{m}^{3}}$ & $34 \frac{\mathrm{kg}}{\mathrm{m}^{3}}$ \\
\hline $\begin{array}{c}\text { Electric current density of } \\
\text { electrode }\end{array}$ & $289 \frac{\mathrm{A}}{\mathrm{m}^{2}}$ & $295 \frac{\mathrm{A}}{\mathrm{m}^{2}}$ \\
\hline $\begin{array}{c}\text { Distance from the surface of } \\
\text { electrolyte }\end{array}$ & $70 \mathrm{~mm}$ & $510 \mathrm{~mm}$ \\
\hline $\begin{array}{c}\text { Copper concentration of the } \\
\text { outlet electrolyte }\end{array}$ & $30.5 \frac{\mathrm{kg}}{\mathrm{m}^{3}}$ & $30.1 \frac{\mathrm{kg}}{\mathrm{m}^{3}}$ \\
\hline
\end{tabular}

In Fig. 5, the concentration of copper obtained from the test is shown in comparison with the copper concentration obtained from the simulation at the two stages A and B for the horizontal line between the cathode and the anode. As seen in this figure, the horizontal axis is the distance between the two electrodes from the cathode to the anode and the vertical axis is the copper concentration. At two points close to the electrodes, the deviation of the experimental results from the values obtained from the modeling is greater, which can be due to the difficulty of obtaining a favorable sample near the electrodes at a short distance from them and the turbulence caused by the effect of the micropipette near the wall of the electrodes. Because variations in the concentration close to the cathode are very high, small disturbances caused by the test device can drastically affect the concentration.

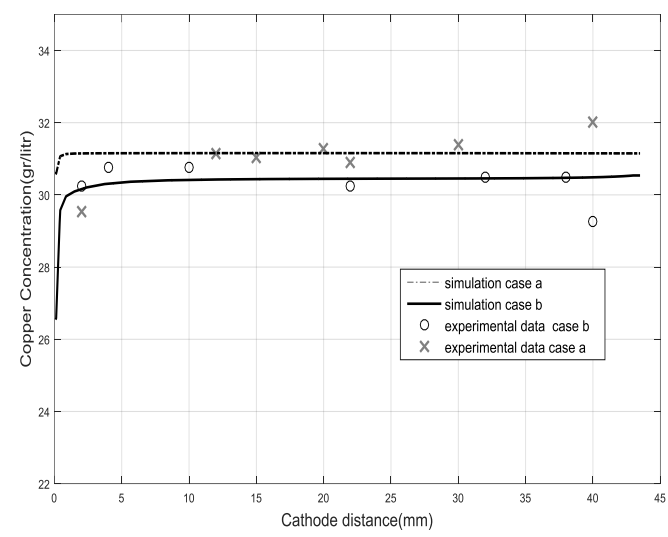

Fig. 5. Copper concentration on the horizontal line in the middle of the electrodes.

Fig. 6 presents the concentrations obtained from the experiments in comparison with the concentration obtained from the simulation at the two stages A and $\mathrm{B}$ for the vertical line from the electrolyte to the cell floor. As shown in this figure, there is very little deviation between modeling and testing, even in cell conditions characterized by severe recirculation and turbulence.

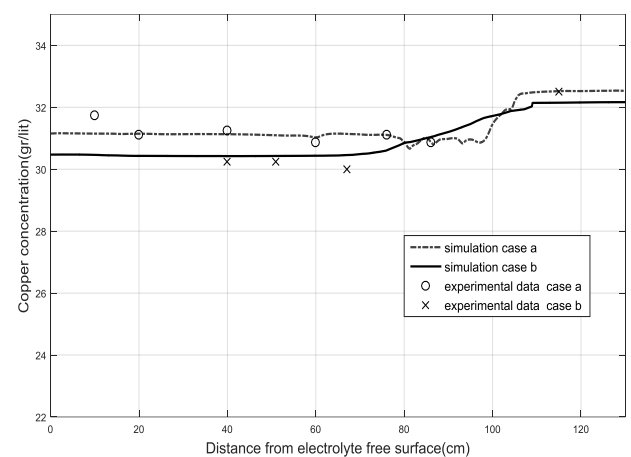

Fig. 6. Copper concentration on the vertical line between the two electrodes, the lines representing the copper concentration obtained from the simulation, and the points representing the experimental data for samples $A$ and $B$.

The deviation of experimental results from the modeling results is defined by Eq. (45):

$\operatorname{Err}=\sum_{i=1}^{n} \frac{\left|C_{i}^{\text {experimental }}-C_{i}^{\text {simulation }}\right|}{C_{\max }-C_{\min }}$

Where $\mathrm{n}$ is the number of sampling on each line inside the cell and the highest concentration is related to the inlet concentration and the lowest is calculated at the cathode boundary layer. The calculations show a deviation of $2.6 \%$ for the test of stage $\mathrm{A}$ and $1.9 \%$ for the test of stage B on the horizontal line and $0.84 \%$ for the test of stage A and $2.85 \%$ for the test 
of stage B on the vertical line.

\section{Modeling Results}

In this section, the results of cell modeling have been investigated. The copper concentration at the entrance is $C_{i n}=36 \frac{\mathrm{kg}}{\mathrm{m}^{3}}$ and it is exited from the outlet by discharging its copper on the cathode plates. In Fig. 7, different regions are observed in terms of copper concentration. This figure shows that the black layer with a concentration of more than $35 \frac{\mathrm{kg}}{\mathrm{m}^{3}}$, and then the white layer with a concentration of $34 \frac{\mathrm{kg}}{\mathrm{m}^{3}}$ to $35 \frac{\mathrm{kg}}{\mathrm{m}^{3}}$ have the highest concentrations of copper and these layers form the volume of the lower area of the cell and under the cathodes and anodes and transfer the copper to the higher parts by natural convection mass transfer. Fig. 8 demonstrates the total fluid velocities by color processing. Inlets and outlets have the highest speed in the cell with black color and velocity of about $0.2 \frac{\mathrm{m}}{\mathrm{s}}$, and after that, spaces near the anodes and the cathodes and between them have the highest speed in the cell at a speed of about $0.05 \frac{\mathrm{m}}{\mathrm{s}}$ to $0.2 \frac{\mathrm{m}}{\mathrm{s}}$. In most of the sub-electrode volumes that have the highest copper concentration, the speed is very low. As a result, the transfer of copper from the cell floor to higher layers is performed by mass transfer caused by the molecular penetration.

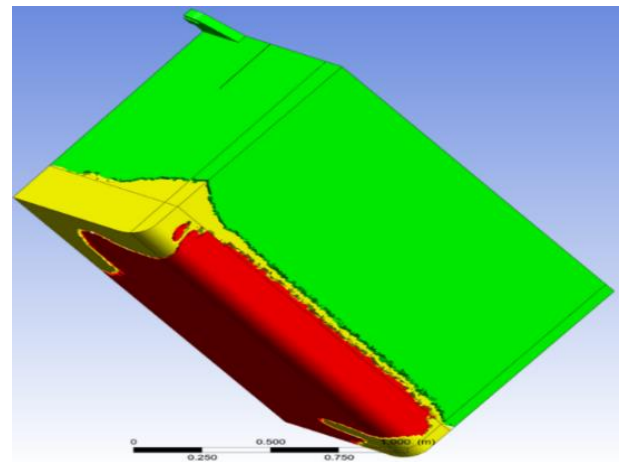

Fig. 7. Color volume processing of the electrowinning cell volume based on copper concentration. Red: more than $35 \frac{\mathrm{kg}}{\mathrm{m}^{3}}$, Green: less than $34 \frac{\mathrm{kg}}{\mathrm{m}^{3}}$ Yellow: between $34 \frac{\mathrm{kg}}{\mathrm{m}^{3}}$ and
$35 \frac{\mathrm{kg}}{\mathrm{m}^{3}}$

Fig. 9 shows the contour of the concentration of oxygen on the free surface from the top view of the electrowinning. The white color indicates an electrolyte with a lower oxygen concentration. As seen in this figure, at the free surface, the release of oxygen bubbles that are accumulated around the anodes causes the electrolyte to flow into and between the electrodes.

In Fig. 10, several streams of flow are shown in the cell inlet. Owing to the laminar flow in the cell floor due to the low velocity (about $0.05 \frac{\mathrm{m}}{\mathrm{s}}$ ) and the consequent small Reynolds number, these streams lead to a laminar flow to the outlet. But the flow streams that permeate the space between electrodes, due to the small space between the electrode $(45 \mathrm{~mm})$ and the presence of natural convection flows at high speeds (about $0.2 \frac{\mathrm{m}}{\mathrm{s}}$ ), are turbulent with great complexity (due to the presence of various forces).

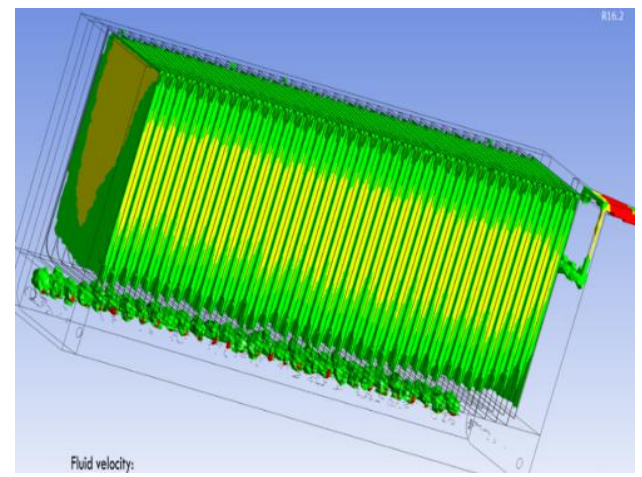

Fig. 8. Color volume processing based on fluid velocity. Red: more than $0.2 \frac{\mathrm{m}}{\mathrm{s}}$, Green: between $0.05 \frac{m}{s}$ and $0.1 \frac{m}{s}$, Yellow: between $0.1 \frac{m}{s}$ and $0.2 \frac{m}{s}$.

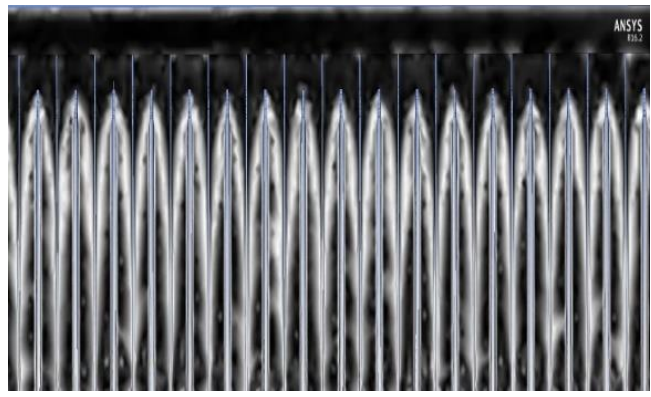

Fig. 9. A view of the free surface of the electrowinning cell, where a darker color indicates more oxygen.

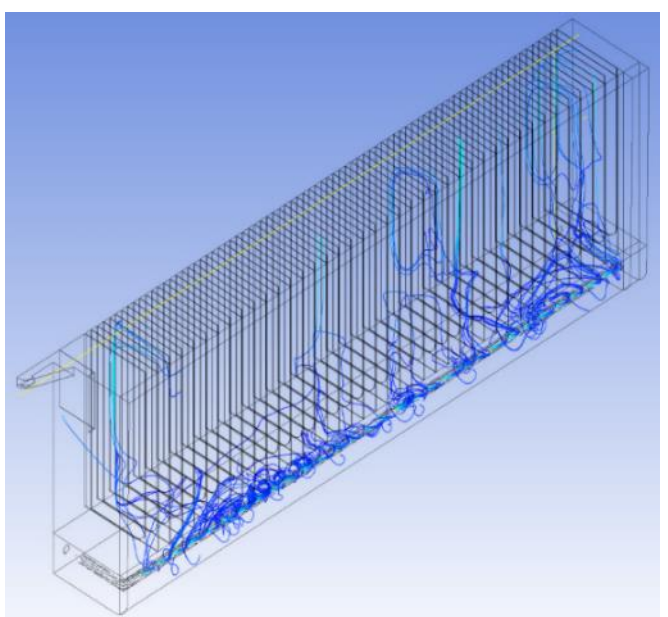

Fig. 10. Flow streams entering the cell from the inlet follow a laminar flow in the path of the cell floor to the outlet, and if permeated into the space between the electrodes, it flows in a very complex and turbulent stream.

Fig. 11 depicts the contour of copper concentration 
on the plane in the middle of the two electrodes According to Fig. 12, the energy of kinetic turbulence is higher in regions having higher speeds, especially near the anodes. Fig. 13 represents the vertical velocity in the space between the two electrodes in both global simulation (A) and local simulation (B). The velocity of the left side (anode) is high because of the drag caused by the movement of bubbles. In the middle, owing to the rotation of the flow, the velocity decreases and the flow direction goes down. On the right side, due to the floating force caused by the copper discharge, the velocity goes upside slightly near the cathode. As shown in this figure, details are accurately observed in the local simulation. The average relative error is defined by Eq. (46):

err $=\frac{\left.\sum_{n} \Delta V\right|_{\text {Case }} ^{\text {Case lobal }} \text { local }}{n \cdot V_{\max }}$

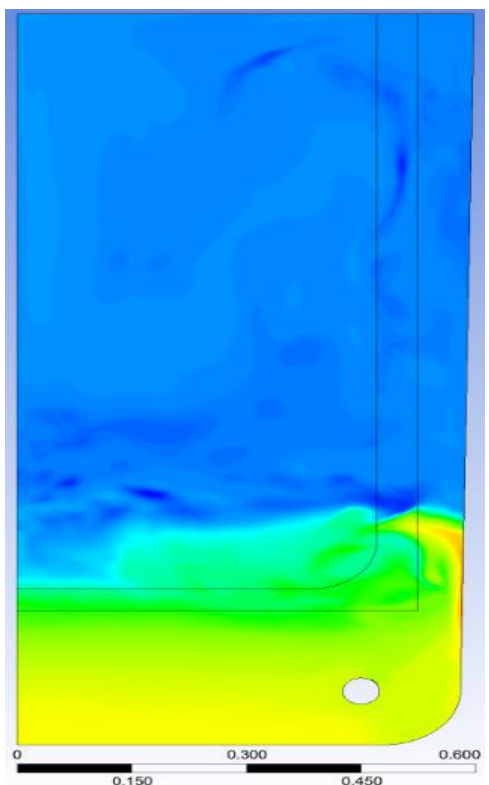

Fig. 11. Contour of copper concentration on a plane in the middle of the anode and cathode plates. A lighter color indicates a higher copper concentration.

Where $\mathrm{n}$ is the number of points calculated between two anodes and cathodes in both models, equal to 100. The calculations showed an average relative error of $7 \%$ for the global simulation relative to the local simulation. However, the relative error between the two simulations in some places reached up to $30 \%$ locally.

In Fig. 14, different values of $k d_{n}$ are shown. $k d_{n}$ Represents the mass transfer coefficient of copper in the various fluid flows presented in Eq. to the cathode as the cathode thickness increases or, equivalently, the cathode distance decreases. As can be seen, changing the cathode thickness has very little positive effect on the mass transfer coefficient. The second observable point is the agreement of the results with the empirical relation of the mass transfer coefficient in the undeveloped turbulent region. The deviation of the simulation results from the empirical relation is $0.5 \%$. The mass transfer coefficient of industrial electrowinning cells can be estimated from the average of annual output due to many instabilities and changes in conditions such as electric current, concentration, temperature, inlet, and outlet flow rates, and intrusive ions during copper production. Average daily production amount according to the annual report was 18.7 tons. Using Eqs. (19) and (21), the one year average mass transfer coefficient according to Eq. (43) is obtained.

$\overline{k d}=\frac{\overline{N_{20}}}{\left(C_{c u(b u l k)}-C_{c u(\text { surface })}\right)_{20}}=2.1 \times 10^{-6} \frac{\mathrm{m}}{\mathrm{s}}$

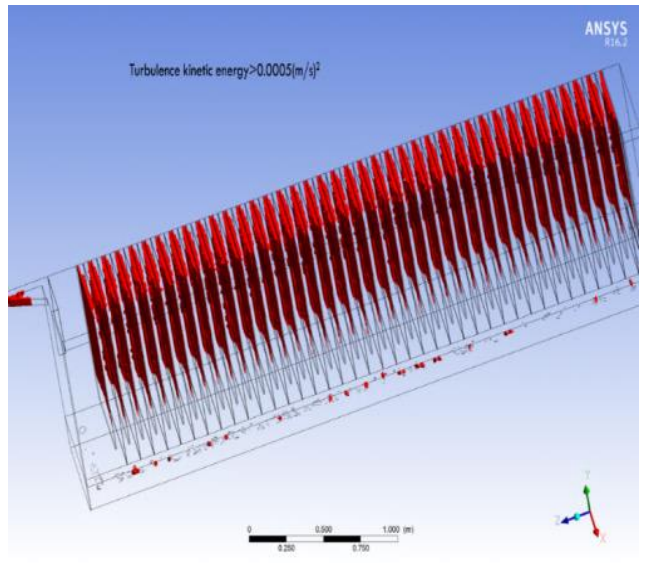

Fig. 12. Color processing of the volume based on turbulent kinetic energy.

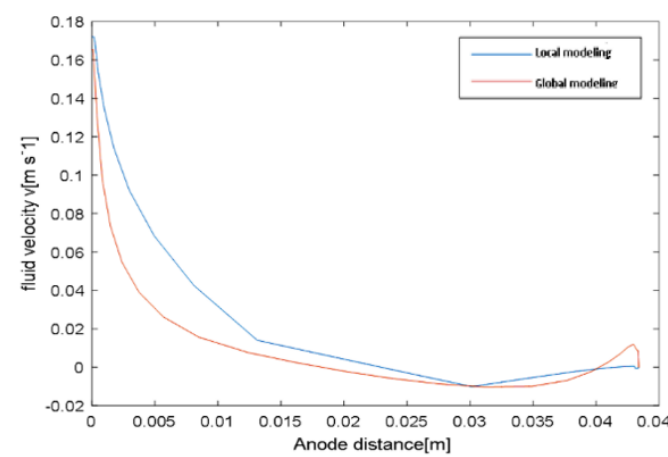

Fig. 13. Vertical velocity in the vertical line between the anode and cathode plates. Red Line) Global simulation, Blue Line) Local simulation.

Where $\bar{x}_{.20}$ is the corrected average of $20 \%$ of the parameter $x$. The reason for using this average is the removal of abnormal data such as production problems, stoppages, and power outages. The average annual mass transfer coefficient was accordingly obtained for several copper production plants worldwide in Beukes and Badenhorst (2009). Table 3 comparison the data of (Beukes and Badenhorst, 2009) with the mass transfer coefficient obtained for the Miduk Copper Complex demonstrates that the mass transfer coefficient of the Miduk plant is close to that of different factories worldwide.

One way to prevent acid mist is sparging air bubbles 
into the cell. Causing the electrode interval to be more turbulent and rotational, air spray into the cell can also increase the mass transfer coefficient and, thereby, the limited electric current density and, consequently, reduce the formation of nodules on the cathode surface and may increase surface quality.

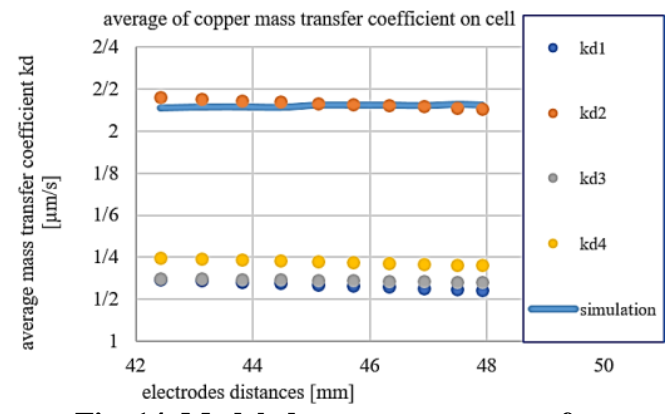

Fig. 14. Modeled average mass transfer coefficient of the copper cell in change of electrode distance versus empirical relationships of different flow regime.

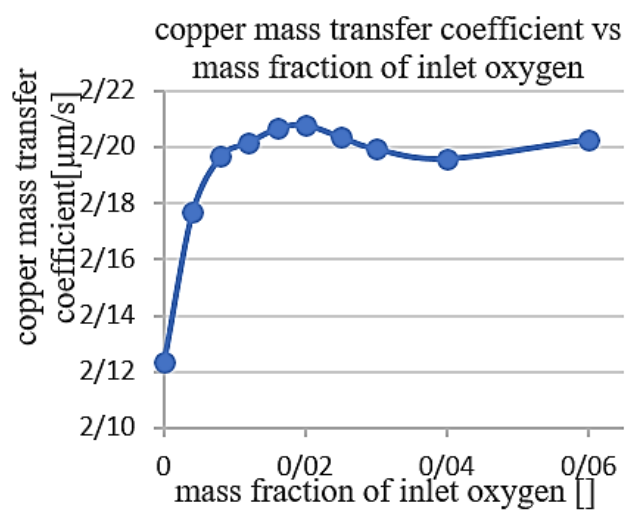

Fig. 15. Average mass transfer coefficient variation for different the mass fractions of oxygen at the inlet.

Since the fluid conditions of the oxygen bubble vs air in the fluid are same approximately. Therefore, it is further investigated to increase the copper mass transfer coefficient by adding oxygen bubble through inlet instead of air. The reason for this simplification assumption is to increase the dissolution rate due to the non-fuzzy modeling. Hence, in the following, the increase in copper mass transfer coefficient by adding oxygen bubbles through the inlet is investigated.

According to the study (Najminoori et al. 2015), in air spray from the inlet, a manifold can be manufactured which can optimally feed the cell with a controllable mass fraction of air relative to the electrolyte and the specific bubble size. The present paper deals with the simulation of oxygen sparging from the inlet into the cell. In adding oxygen bubbles from the inlet, the assumptions were considered is first the size of the bubbles is equal to the bubbles created in the electrowinning process and they are the same size. Second assumption is oxygen enters the cell directly from the inlet with physical conditions of oxygen and velocity of the fluid. Given the assumptions, the only change needed to be made to the model is to change the input boundary condition from one-phase to two-phase fluid. This change will vary the $S_{N}$ value in Eq. 5 for the input boundary condition. In this paper, some changes are made to the modeling and the obtained modeled is solved for different mass fraction values, whose results will be discussed in the following. As shown in Fig. 15, the mass transfer increases by up to $5 \%$ as the bubble is sprayed through the inlet into the electrowinning cells, but then the mass transfer will be almost constant. Another case investigated by the simulation is the effect of increasing the inlet flow rate to the cell as shown in Fig. 16. Increasing the inlet flow rate speeds up the flow of fluid inside the cell around the electrodes but has little effect on the electrode interval, mainly due to the large effect of natural flow induced by the difference in concentration near the cathode and rotational fluid flow induced by the drag force of the bubbles. As a result, there is no expectation of an increase in the mass transfer coefficient. As can be seen in Fig. 16, the mass transfer coefficient has a very negligible positive change in the $10 \%$ increase applied to the electrowinning cells. The effect of the temperature of the electrolyte entering the cell on the average mass transfer of the cell is also studied in the simulation, as shown in Fig. 17 . Given that the gas density, electrolyte density, the mass diffusion coefficient of copper in the electrolyte, electrolyte, and gas viscosity are a function of temperature when the inlet electrolyte temperature is raised, these are considered by the relevant equations. Figure 17 compares the temperature variation of the electrolyte obtained from the modeling and the experimental relationships. The blue line indicates the simulation results and the red line represents the Sherwood relation for turbulent and undeveloped fluid flow. The average deviation is $7.4 \%$.

Inlet electrolyte of cell Vs copper mass transfer coefficient

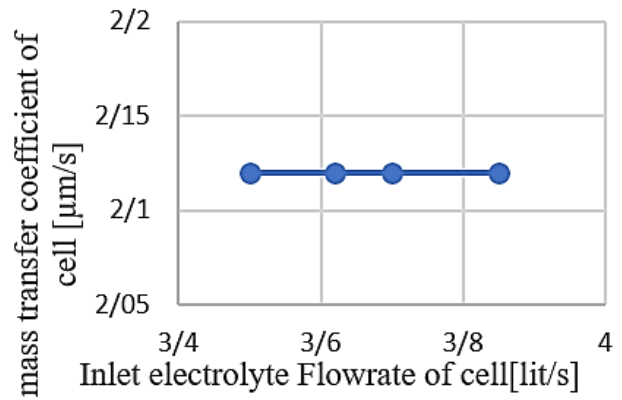

Fig. 16. The effect of increasing electrolyte inlet flow rate on the average cell mass transfer coefficient.

Figure 18 depicts the mass transfer coefficient variation on the middle line of the cathode. In this figure, from the bottom of the cathode upward, the mass transfer coefficient decreases at the bottom 10 $\%$ of the cathode, then is almost constant and increases at approximately top $30 \%$ of the cathode. In a narrow region about $10 \mathrm{~cm}$ top of the cathode, there is a small area where the mass transfer coefficient declines sharply and then increases, due 
to the return rotational fluid flow from the cell surface and a temporary decrease in the fluid velocity of the cathode surface. This change in the level of the produced cathode creates a qualitative problem for the surface, called the ridge. This is illustrated in Werner's study (Werner 2017) by examining a diagram similar to Fig. 18.

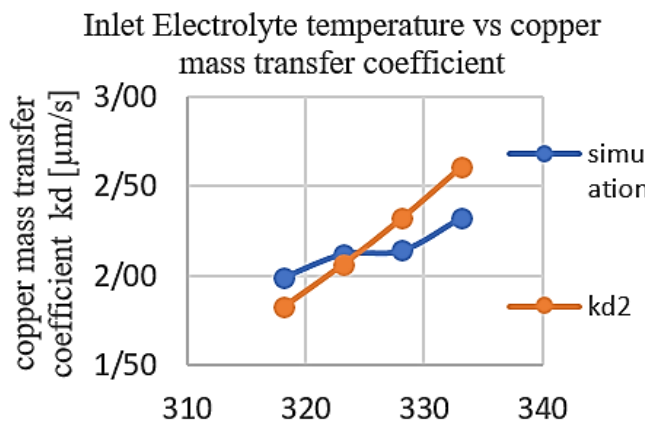

Inlet electrolyte temperature $[\mathrm{K}]$

Fig. 17. Effect of temperature of the electrolyte entering the cell on the average mass transfer coefficient of the cell.

local mass transfer coefficient of points on vertical center line

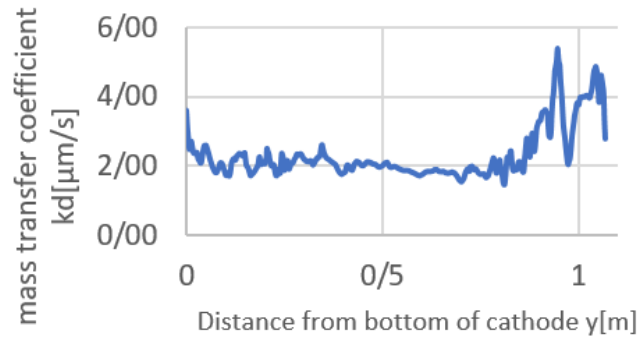

Fig. 18. Local mass transfer coefficient of the middle line of the cathode from the bottom.

\section{Conclusion}

In this paper, first, the Miduk electrowinning cell was thoroughly modeled. In order to increase the accuracy of this modeling, for the first time, the local simulation was employed in parallel to the global simulation. By combining these two types of global and local simulations, in addition to the speed, a great deal of ability to increase accuracy was achieved. The main real consequence of this study is that for the global modeling of an electrowinning cell, performing a local simulation in parallel is required to increase the accuracy and speed of the solution. In this modeling, velocity fields, copper and acid concentrations, turbulence energy, the volume fraction of oxygen bubbles, and pressure in general and high accuracy are obtained. The maximum deviation of the modeling results from the experiment is less than 3\%. Then, using the simulation of the Miduk electrowinning cell, the mass transfer in the electrowinning cell was investigated. Obtaining mass transfer coefficients is of absolute necessity for optimizing electrowinning cells in terms of quantity and quality of copper production. In order to validate the obtained mass transfer coefficient, a cell was compared with empirical relationships presented in different papers. The results demonstrated a maximum error of $5 \%$. The next step was to study the effect of reducing the electrode interval in the cell, the effect of applying oxygen spray through the electrolyte inlet into the cell on the mass transfer coefficient, the effect of increasing the electrowinning cell inlet flow rate, and the effect of changing the temperature of the electrolyte entering the electrowinning cells. The results indicated that spraying oxygen at 16 liters per second through the electrolyte inlet increased the mass transfer coefficient by $7 \%$. Increasing the electrolyte inlet flow rate had no effect on the mass transfer of copper to the cathode and increasing the inlet electrolyte temperature increased its mass transfer coefficient such that with a $15^{\circ} \mathrm{C}$ increase in temperature the mass transfer coefficient rose by about $10 \%$. Finally, the local mass transfer coefficient on the middle line of the cathode from bottom to top was obtained using the model. The results showed that the mass transfer coefficient changed about the top $10 \mathrm{~cm}$ of the cathode, which could affect the surface quality of this region.

\section{ACKNOWLEDGEMENTS}

The authors would like to thank the management of the Miduk Copper Complex for providing the information resources of the Copper Leaching Complex.

\section{REFERENCES}

Alshakarji, R. (2012). Mechanisms of acid mist formation in electrowinning, James Cook University.

ANSYS CFX-Solver Theory Guide (2016).

Beukes, N. T. and J. Badenhorst (2009). Copper electrowinning: theoretical and practical design, Hydrometallurgy Conference 2009, The Southern African Institute of Mining and Metallurgy.

Cifuentes, L. and P. Arriagada (2008). Copper electrowinning in a moving-bed cell based on reactive electrodialysis. Revista De Metalurgia 11

Coleman, S. and S. Roy (2014). Effect of ultrasound on mass transfer during electrodeposition for electrodes separated by a narrow gap. Chemical Engineering Science 113, 10.

Filzwieser, A. (2000). Modelling of the Processes Close to Cathodes in Copper Electrolysis (Modellierung der kathodennahen Vorgänge in der Kupferelektrolyse), Montanuniversität Leoben, Leoben, Austria.

Filzwieser, A., K. Hein and G. Mori (2002). Current Density Limitation and Diffusion Boundary Layer Calculation Using CFD Method. JOM 54, 28-31. 
Fisher, K. G. and R. G. Hughes (1971). Application of periodic current reversal (P.C.R.) to electrolytic copper refining at Mufulira. Transactions of the Institution of Mining and Metallurgy 12.

Geankoplis, C. J. (2003). Transport Processes and Separation Process Principles: (includes unit operations). Prentice Hall Professional Technical Reference.

Gendron, A. and V. Ettel (1975). Hydrodynamic Studies in Natural and Forced Convection Electrowinning Cells. The Canadian Journal of Chemical Engineering 53(1), 36-40.

Graydon, J. and D. Kirk (2001). Suspension codeposition in electrowinning cells: the role of hydrodynamics. The Canadian Journal of Chemical Engineering 69, 7.

Kemminger, A. and A. Ludwig (2013). Modelling the Electrolyte Flow in a Full-scale Copper Electrorefining Tankhouse Cell, Proceedings of European Metallurgical Conference EMC, 795-806.

König, J., Lars Büttner, S. Odenbach, Jürgen Czarske (2011). Velocity Measurements Inside the Concentration Boundary Layer during Copper-Magneto-Electrolysis Using a Novel Laser Doppler Profile Sensor. Electrochimica Acta 56(17): 6150-6156.

Leahy, M. and P. Schwarz (2010). Experimental Validation of a Computational Fluid Dynamics Model of Copper Electrowinning. Metallurgical And Materials Transactions B 41, 14.

Leahy, M. J. and M. P. Schwarz (2014). Flow and Mass Transfer Modelling for Copper Electrowinning: Development of Instabilities along Electrodes. Hydrometallurgy 147-148, 41-53.

Luo, J., P. Jiao, N. Duan, F. Xu and L. Jiang, (2018). Flow Field Characterization in The Vicinity of Vertical Plane Electrodes in a Bench-Scale Zinc Electrowinning Cell. Hydrometallurgy 181, 103-112.

Moats, M. S., J. B. Hiskey and D. W. Collins (2000). The effect of copper, acid, and temperature on the diffusion coefficient of cupric ions in simulated electrorefining electrolytes. Hydrometallurgy 14.

Najim, S. T. (2016). Estimation of Mass Transfer Coefficient for Copper Electrowinning Process. Journal of Engineering 22, 11.

Najminoori, M., A. Mohebbi, K. Afrooz and B. G.
Arabi (2019). The effect of magnetic field and operating parameters on cathodic copper winning in electrowinning process. Chemical Engineering Science 199, 19.

Najminoori, M., A. Mohebbi, B. G. Arabi and S. Daneshpajouh (2015). CFD Simulation of an Industrial Copper Electrowinning Cell. Hydrometallurgy 153, 88-97.

Pourtousi, M., J. Sahu, P. Ganesana, S. Shamshirband and G. Redzwan (2015). A combination of computational fluid dynamics (CFD) and adaptive neuro-fuzzy system (ANFIS) for prediction of the bubble column hydrodynamics. Powder Technology 274, 466-481.

Raju, C. R., G. J. Raju and C. V. Rao (1967). Effect of Pulsation on Mass Transfer Coefficients Ionic Mass Transfer. Indian Journal of Technology 5, 5 .

Raju, G. J. V. J., P. Venkateswarlu, S. S. Rao and C. B. Sarma (1979). Effect of longitudinal distance of electrode on the ionicmass transfer on the confining wall of a stirred vessl. Indian Journal of Technology 5, 5.

Rao, V. P. (1974). mass transfer cylinders rotating about parallel axes, Andhra university, woltair India

Reining, R. (2018). Titration handbook: SI Analytics.

Schwarz, M. P. (2012). Improving Zinc Processing Using Computational Fluid Dynamics Modelling-Successes and Opportunities. Minerals Engineering 30, 12-18.

Sigrist, L. and O. Dossenbach (1979). Mass Transport In Electrolytic Cells With Gas Sparging. International Journal Heat and Mass Transfer 22, 7.

Soliman, H. and A. A. El-Moneim (2011). Electrowinning of Copper Using Rotating Cylinder Electrode Utilizing Lead Anode. Scientific Research 3, 19.

Subbaiah, T., P. Venkateswarlu, R. Das and G. Raju (1995). Mass-transfer conditions at a cathode support plate in an electrochemical cell. Chemical Engineering Processing: Process Intensification 34(6): 495-501.

Sutherland, W. (1893). the viscosity of gases and molecular force. Philosophical Magazine: 25.

Werner, J. M. (2017). Modeling and Validation for Optimization of Electrowinning Performance, The University of Utah, 219. 